\title{
2002: consolidação do compromisso científico dos Arquivos Brasileiros de Oftalmologia e merecidas reverências
}

\author{
Harley E. A. Bicas, Cristina Muccioli, Mauro Goldchmit, Mauro S. O. Campos, \\ Samir J. Bechara, Vital Paulino Costa
}

Como já vem se tornando tradicional, ao se abrir mais um volume de nova coletânea de títulos com que registramos o avanço e a consolidação da ciência oftalmológica, o primeiro editorial de cada ano de nossa revista rende homenagens e agradecimentos aos seus colaboradores "ad hoc".

Quem são essas pessoas? Boa parte é gente jovem, mas que, não obstante, tem se feito distinguir pelo tipo de trabalho realizado, tornando-se qualificada para opinar sobre apresentações de assuntos que bem conhecem. Jovens, mas já respeitáveis autoridades.

São, também, generosas na disponibilização de seus tempos. Aliás, não só elas, mas também nossos Conselheiros Editoriais, propriamente assim entitulados, oferecem análises cujas extensões e substâncias denotam exames minuciosos, dedicados, verdadeiras aulas de como se pode aprimorar o texto e a estrutura do trabalho. Isso exige sacrifício de outras tarefas, ou de parcelas de descanso, ou lazer.

Aliás, aí se identifica o primeiro propósito desse trabalho de bastidores: selecionar matérias, separando as aproveitáveis daquelas cuja publicação não se justifica (quer por ser o conteúdo de interesse alheio ou distante do da Oftalmologia, quer por ser deficientemente composto, quer por traduzir uma contribuição perfunctória). Os leitores, assim, são providos de informações mais úteis, originais, construtivas, enquanto os autores não atendidos com a publicação de seus artigos são preservados da exposição de suas inadequações.

A segunda finalidade desse exame crítico dos artigos, solicitado a nossos analistas editoriais é, ainda, o de ajudar os autores no aprimoramento de seus escritos, orientando-os para correções de toda ordem: estruturas desequilibradas (desenvolvimentos longos e desinteressantes de partes, ou superficiais e sucintos de outras), conteúdos e formas impróprios, incoerências e contradições, ilogicidades e inconsistências, enfim toda uma enorme quantidade de condições redatoriais, cujas normas nem sempre são obedecidas.

Aprende-se a redigir trabalhos científicos: isso não é espontâneo; aprende-se, igualmente, a lê-los com visão crítica; aprende-se, finalmente, a aceitar e acolher sugestões formuladas, para a modificação de trabalho enviado a uma revista. Cursos de pós-graduação, leituras de manuais de redação e estilo, aulas sobre estruturação e normas de preparação de artigos científicos além da própria participação como autores e revisores constroem, lenta mas inequivocamente, uma nova classe de gente que faz ciência em nosso país.

Ainda há erros, sem dúvida (e provavelmente sempre ocorrerão, dada a falibilidade humana). Ainda há análises superficiais, ou sem engenho construtivo, que pouco contribuem para com os autores e leitores. Ainda há pessoas que se sentem ofendidas ao receber críticas, como se elas não fossem para ajudá-las, ou como se não contivessem opiniões imparciais. É verdade que também, ainda, existem críticas indevidas; ou devidas, mas ácidas e erosivas. Mas já estamos chegando, como "emergentes", ao nível de conhecimento e compreensão dos povos mais desenvolvidos.

E por enquanto, como parte da tradição, nossos sinceros cumprimentos, agradecimentos e reverências, a nossos Conselheiros Editoriais, a que se somam:
Abelardo S. Couto Jr.
Acácio Alves de Souza Lima Filho
Acácio Muralha Neto
Adamo Lui Neto
Alexandre Chater Taleb
Alfredo Tranjan Neto
Ana Maria Marcondes
André Luís Borba da Silva
André Marcelo V. Gomes
Andréa Araújo Zin
Augusto Paranhos Júnior
Breno Barth
Canrobert Oliveira
Carlos Eduardo Leite Arieta
Carmo Mandia Jr.
César Lipener
Christiane Rolim
Cláudio Alberto M. Silveira
Consuelo Bueno D. Adan
Daniel Segulen
Denise de Vuono Chinzon
Denise Fornazari de Oliveira
Edméa Rita Temporini
Edna Sbrissa
Edson Mori
Eduardo Ferrari Marback 
Eduardo Melani Rocha

Eduardo Minelli

Eduardo Sone Soriano

Élcio Hideo Sato

Eliana A. Forno Velasco

Eurípedes da Mota Moura

Flávio Jaime da Rocha

Francisco Eduardo Lemos Lima

Francisco Valter da Justa Freitas

Frederico V. S. Pena

Ítalo Mundialino Marcon

Jair Giampani Jr.

João Alberto Holanda de Freitas

João Amaro Ferrari Silva

João Antônio Prata Jr.

John Helal Jr.

José Augusto Cardillo

José Paulo Cabral Vasconcellos

José Wilson Cursino

Joyce Hisae Yamamoto

Juliana Maria F. Sallum

Keila Miriam M. Carvalho

Laurentino Biccas Neto

Lucia Melega Re

Luiz Alberto S. Melo Jr.

Magno Antonio Ferreira

Marcelo Luis Ochiutto

Márcia Beatriz Tartarella

Marco Aurélio Lana Peixoto

Marcos Wilson Sampaio

Maria Aparecida Onuki

Maria Auxiliadora M. F. Sibinelli

Maria Cristina Martins

Maria Cristina N. Dantas

Maria do Carmo Pinheiro

Maria Teresa Bonanomi

Maria Kiyoko Oyamada

\author{
Marilisa Nano Costa \\ Marta Beatriz F. Sartori \\ Martha Maria M. Chojniak \\ Mauro Nishi \\ Mauro Waiswol \\ Milton Seiyu Yogi \\ Mirian Skaf \\ Moacyr P. Rigueiro \\ Nilo Holzchuh \\ Niro Kasahara \\ Norma Allemann \\ Paiva Gonçalves Neto \\ Paulo André Polisuk \\ Paulo Gilberto Jorge Fadel \\ Paulo Góis Manso \\ Paulo Henrique A. de Morales \\ Renato Giovedi Filho \\ Ricardo Belfort \\ Ricardo Lewinsky \\ Roberto Freire Santiago Malta \\ Roberto Lauande Pimentel \\ Rosa Maria Graziano \\ Rosana Nogueira P. Cunha \\ Rosane da Cruz Ferreira \\ Ruth M. Santo \\ Seiji Hayashi \\ Simone H. von Faber Bison \\ Solange Rios Salomão \\ Teruo Aihara \\ Tomás F. Scalamandré Mendonça \\ Vera Lúcia D. Monte Mascaro \\ Virgílio Centurion \\ Walter Takahashi \\ Walton Nosé \\ Wilmar Roberto Silvino \\ Wilson de Freitas \\ Zélia Maria S. Corrêa
}

